\title{
Organisational rhetoric in the prospectuses of elite private schools: unpacking strategies of persuasion
}

\author{
Paula McDonald \\ School of Management \\ Queensland University of Technology \\ Email: p.mcdonald@qut.edu.au \\ Robyn Mayes \\ Curtin University of Technology \\ Barbara Pini \\ Curtin University of Technology
}

\begin{abstract}
Schools have seldom been examined by scholars in studies of organizational sites. Yet schools and the educational context in which they operate, offer potentially important insights into how organizations use rhetoric in their communications to persuade audiences and leverage advantage in the marketplace. This study, which utilises rhetorical analysis to examine the persuasive, yet ambiguous strategies used in 65 school prospectuses in Australia, revealed six strategies consistently used by schools to leverage competitive advantage and persuade internal and external audiences: identification, juxtapositioning, bolstering or self-promotion, partial reporting, selfexpansion and reframing or reversal. As well as illustrating how schools operate in the context of marketisation and privatization discourses in $21^{\text {st }}$ century education, the organizational theory and methods utilised for the research demonstrates how rhetorical strategies draw on, as well as reproduce, socio-political and cultural discourses around economic and social privilege.
\end{abstract}

Keywords: Schools, Marketisation of Education, Prospectus, Organizational Rhetoric

Schools have seldom been examined by scholars in studies of organizational sites, yet they share many features and functions of organizations which operate in a neo-liberal market. Fundamentally, policies which underpin the privatization and marketisation of education - global phenomena over the past decade - rework the purposes and motivations of educational practitioners to reflect entrepreneurism, competitiveness and being 'business-like' (Cribb and Ball 2005). Further, along with a myriad of other organizational functions (e.g., competing for and attracting committed employees; adapting to changing market conditions) many private schools must now attempt to 
position themselves in such a way as to be competitive against schools with similar target markets. This phenomenon has resulted from a systematic dismantling of centralized educational bureaucracies to systems that emphasize parental choice and competition between schools, thereby creating quasi-markets in educational services (Whitty and Power 2000).

One method that organizations use to communicate to relevant audiences is through the use of persuasive, rhetorical strategies. In contrast to more mainstream theorizing, rhetorical analysis allows for organizing principles to be put under critical scrutiny (Kuronen et al. 2005). A visible and persuasive form of communication used by private schools, and one which is ideally placed to reveal organizational rhetoric, is the prospectus. Prospectuses provide insight into the broader educational values espoused by these organizational sites and are revealing in the way they engage with the discourses currently underpinning early twenty-first century education (Symes 1998). This study uses rhetorical analysis to examine school prospectuses in Australia in the context of broader educational discourses. However, the research also has relevance across the field of organizational studies. The private education sector provides a potentially important empirical site in which to illustrate how organizations more generally, use rhetoric to persuade audiences and leverage advantage in the marketplace; as well as how rhetorical strategies draw on hegemonic discourses in broader cultural politics and reproduce and reinforce the platforms and emphases associated with these discourses.

We begin by defining and characterising organizational rhetoric in the context of our study, and introducing the rhetorical strategies which guide our conceptualization and subsequent analysis. We then provide the context for the study by detailing the current educational policy environment in Australia. An understanding of the broader 
educational context allows for an analysis of the mutually constitutive and complex set of connections between Grand- or Mega-Discourses to legitimate our arguments, as well as the micro-discursive strategies in the texts themselves (Grant and Hardy 2003; Symon 2005). The empirical section of the article reveals six rhetorical strategies which predominate in 'elite' private school prospectuses which make important truth claims that have significant currency in the context of the contemporary cultural politics of education. By revealing the rhetorical strategies used, we provide insights about what Ezzemel and Willmott (2008) refer to as several prominent 'discourses of truth' (in the context of education for example; 'choice' and the efficiency of privatization). This approach takes as its premise the conception of knowledge as performative, and as an enriching alternative to a realistic (e.g., economic and behaviourist) interpretation of analysis.

\section{Corporate rhetoric as persuasion}

Located on a political stage and calculated to persuade or influence an audience toward some end, rhetoric is the humanistic tradition for the study of discourse (Cheney et al. 2004). Organizational rhetoric is found in formal, public messages and discourses such as in speeches by Chief Executive Officers, public relations campaigns and mission statements (Cheney et al. 2004; Swales and Rogers 1995) and has been applied to numerous aspects of organizational life, including human resource management (Legge 1995), organizational control (Linstead 2001) and employment relations (Hamilton 2001). While classic rhetoric emphasized the intentionality of the speaker, focusing on persuasion through argumentation (Warnick 2000), contemporary rhetoric examines communication situations in which intentions are not tied to one person or decision-maker (Allen 2004; Cheney et al. 2004). Rhetoric helps 
to achieve closure of meanings by plausibly positioning some interpretations as taken for granted or by excluding alternative constructions (Linstead 2001). For the purpose of the current study, organizational rhetoric includes situations in which the likelihood of persuasion as the message effect is context dependent and in which the intent of a message is ambiguous (Cheney et al. 2004).

Cheney et al (2004) outlines 20 rhetorical strategies common in organizational and institutional messages. We utilize these rhetorical strategies in our analysis of prospectuses to closely examine the data set, while being cognizant that each specific strategy may be mobilized in support of a range of broader strategic ambitions or drivers.

\section{Australian education in context: privatization and marketisation}

For schools, a new consciousness about appearance was accompanied by the adoption of corporate managerialist practices tethered to privatisation and marketisation (Marginson 1993). While the former refers to situations where the funding, provision or regulation of education are progressively moved away from the state to the private sector (Tooley 2003), the latter is characterized by the adoption of free market practices (Hartley 2008). These trends have also been well documented phenomena in the UK, Canada, New Zealand, the United States and South Africa (e.g., DavidsonHarden and Majhanovich 2004).

Educational policy arising from the dual processes of privatisation and marketisation imported a new set of virtues around efficiency and accountability and the modernising influence of business, while displacing an older, outmoded set which was seen as bureaucratic or based on defensive, self-interested professional groups (Cribb and Ball 2005). The marketisation of education emphasises competition, contestability 
and performance-management, the results of which become publicly available to would-be choosers of a service-provider (Hartley 2008). Importantly, in terms of the widespread acceptance of these ideological shifts, the marketisation position is argued on the grounds of parental choice, equity and democratic principles, explaining the broad basis of support from consumers and suppliers, and liberals alongside disadvantaged social and ethnic groups (Kwong 2000). In Australia as elsewhere, much criticism has been levelled at shifts in educational policies associated with privatization and marketisation (e.g., Brighouse 2000), with many scholars suggesting distinctly negative social consequences of a reconfigured educational environment.

\section{Communicating through prospectuses}

The discourse of the prospectus attempts to strike a resonance with its community of potential clients in a way that parallels the educational expectations of its readers, resonating with their ideologies (Symes 1998). Almost universally it seems, prospectuses emphasise the high academic achievement of students, offering future students positional advantage over their peers, alongside a begrudging acknowledgement of students who lie outside the academic trajectory (Symes 1998). Propsectuses also suggest that for successful academic students, scholastic identity and self-esteem is unproblematic, while self-esteem for the not-so-academic can be recuperated by out-of-classroom skill development such as sports and other extracurricular activities (Meadmore and Meadmore 2004). Symes (1998) found that denominational schools tend to emphasise religious themes through copious illustrations of the ecclesiastical architecture and pictures of chapels and stained-glass windows. Meadmore and Meadmore (2004) also identified religiosity as a significant 
theme, but through the judicious linking of spiritual and emotional constructs such as emotional literacy and 'intelligence', good character, and citizenship.

Allan (2009: 155) demonstrated prominent gendered theme in prospectuses in a study of an upper middle class girls school. Girls were expected to make themselves 'sassy, sexy and successful', but only within the bounds of being respectable, feminine, heteronormative, 'ladies'. Meanwhile, Meadmore and Meadmore (2004) suggested that prospectuses presented a case for young men to develop a relatively narrow repertoire of soft skills (sensitivity, empathy, altruism and a positive outlook) in order to prosper as leaders and to survive in a personal sense.

While the design, production and distribution of prospectuses is only one of a number of avenues available for schools to 'establish a dialogue in order to create consciousness, understanding and appreciation of the strategic goals' (Van Riuel 2003: 168), prospectuses are likely to be a key strategy among these. For example, prospectuses require the input of multiple stakeholders, demand significant expenditure from school budgets, are widely distributed, and allow for multiple messages directed at internal and external audiences. Further, prospectuses are particularly rich sources of data for the analysis of rhetoric because their language, images, format, layout, colours and typesetting can all be examined to provide a detailed picture of communication, persuasion and self-promotion.

\section{Methods}

The objectives of the study were three-fold and our empirical analysis departs from existing literature in several ways. First, we examined the way schools, as organizational sites, employed specific rhetorical strategies through the use of organizational rhetorical frameworks. Consistent with a fundamental premise of 
rhetoric outlined in the literature (Cheney et al. 2004; Cheney and Christensen 2001), we conceptualized the messages as persuasive communications with both internal (teachers, administrative staff, current students) and external (prospective parents, extended families, policy makers, the media) audiences. Second, given continuing and significant changes to educational policy in Australia, we highlight the rhetorical strategies used against the context of current educational trends and policy which mobilise specific discourses. Our third objective was to contribute to debates in the broader field of organization studies by revealing how rhetorical strategies deployed in organizational communications draw on hegemonic discourses in the politicocultural environment characteristic of industrialized societies and how rhetoric, in turn, reproduces and reinforces the platforms and emphases of these discourses. We explored the following research questions:

1. What rhetorical strategies of persuasion do private schools use in their prospectuses to attract prospective students? What ideological work do they do?

2. What do the rhetorical strategies mask, in terms of broader education frameworks? What are the points of tension and concern?

3. What are the connections between organizational rhetorical strategies and the context of broader politico-cultural discourses?

We examined the prospectuses of schools at the 'elite' end of the private school market, whose fees were greater than \$AUS10,000 per annum. We first conducted a web-based search of non-state high schools across three Australian states (Queensland [Qld], Western Australia [WA] and New South Wales [NSW]) in order to gain national breadth. We then contacted each school and requested a prospectus to be sent to us in the mail, all of whom complied with our request. Typically, these were in 
booklet or folder form on very high quality paper and around 14 pages in length. Their basic structures were broadly similar and included a 'message from the principal', demographic and historical information about the school, a description of the schools' accessibility and location, and information about the religious values, curriculum, and code of behaviour. Table 1 details the sample characteristics.

Table 1: Relevant characteristics of sample prospectuses $(\mathrm{N}=65)$

\begin{tabular}{|l|l|l|l|l|l|}
\hline \multicolumn{1}{|c|}{ Characteristic } & $\begin{array}{l}\text { Number of } \\
\text { Schools }\end{array}$ & $\mathbf{\%}$ & Characteristic & $\begin{array}{c}\text { Number } \\
\text { of Schools }\end{array}$ & $\%$ \\
\hline Religious affiliation & & & Grades offered & & \\
\hline Grammar & 1 & 2 & Primary-yr 12 & 63 & 97 \\
\hline Presbyterian/Uniting & 12 & 18 & $\begin{array}{l}\text { High school (yr 8- } \\
12)\end{array}$ & 2 & 3 \\
\hline Inter-denominational & 2 & 3 & Gender & & \\
\hline Lutheran & 1 & 2 & Co-educational & 17 & 26 \\
\hline Anglican & 25 & 38 & Boys only & 19 & 29 \\
\hline Non-selective & 10 & 15 & Girls only & 29 & 45 \\
\hline Catholic & 7 & 11 & Fee range & & \\
\hline Methodist & 1 & 2 & $\$ 10,000-\$ 12,499$ & 13 & 20 \\
\hline Baptist & 1 & 2 & $\$ 12,500-\$ 14,999$ & 16 & 25 \\
\hline Jewish & 4 & 6 & $\$ 15,000-\$ 17,499$ & 10 & 15 \\
\hline Church of England & 1 & 2 & $\$ 17,500-19,999$ & 16 & 25 \\
\hline & & & $\$ 20,000+$ & 10 & 15 \\
\hline
\end{tabular}

Following Rose (2001: 150), we began the analysis by becoming immersed in the prospectuses. We then searched for any rhetorical strategies that were consistent with the 20 categories of organizational rhetoric identified by Cheney and colleagues (2004). Importantly, the framework incorporates strategies used in a wide variety of organizational situations, such as press releases responding to a crisis, and we therefore did not expect to find evidence in all the a priori categories.

\section{Results}


Identification. Identification - linking one issue with another indivisible issue - was illustrated most frequently in relation to academic achievement. Academic success was attributed to the specific pedagogical practices at the school, such as in the following statement from a co-educational school in NSW: "our academic success stems from our ability to stimulate curiosity and instil a love of learning in our students". Academic success was also linked inextricably with other areas of human development; in particular physical, emotional and cultural. References to economic or financial development however were absent. Hence, while schools were eager to communicate to their audiences that attending students were highly likely to achieve academic success, the suite of developmental offerings were often linked with teaching children how to be generous citizens concerned with social justice: "[School] places special emphasis on community service as a means of providing enriching experiences that extend students' understanding of the wider world and their place in it" (Presbyterian girls school, WA). In this way, institutional gain was side-stepped and the school was positioned as useful and 'giving' to the community. Juxtapositioning. Prospectuses used juxtapositioning in aligning first, tradition and innovation, second, religion and critical enquiry, and third, (for some girls schools), professional careers and motherhood. Prospectuses often dedicated at least one page to describing the history of the school, along with a statement reflecting the continuity of values and principles of a time past: “Today's school remains true to Miss Roseby Ball's founding principles" (Anglican girls school, NSW). Alongside historical photos of school buildings or groups of students, many schools positioned in close proximity, photographs of computer and science laboratories, theatre and musical equipment and state-of-the-art sporting facilities. The most striking example of juxtapositioning traditional and innovative themes was a full-page photograph of a 
floor to ceiling stained glass window in a church, below which sat a female student playing the drums (Anglican girls school, NSW).

Juxtapositioning was also used to align mainstream religious education with other educational virtues. While Catholic schools presented religious-based text and photographs in an explicit, detailed way: “... our girls experience a variety of ways to worship and celebrate their faith:, non-Catholic schools juxtaposed descriptions of religious education with more 'critical' themes, including "reinterpretation... in the context of modern scientific knowledge” (non-denominational boys school, NSW).

Bolstering and self-promotion. Bolstering - a way of building up the status or credibility of the organization - was immediately obvious in the overall appearance of the prospectuses, which used high quality printing materials, glossy, full-page photographs of happy, engaged, well-groomed and attractive students, and an uncluttered format with liberal use of 'white space'. Other formatting techniques used to bolster were the repeated use of the school name and the capitalization of words which were not proper nouns, such as "School", "Sports Program" and "Music Ensembles".

Schools also used bolstering or self-promotion to manage their images of academic and extra-curricula excellence, evidenced in statistics related to state examination results and awards. These were framed around not only securing university entry, but in obtaining students' 'first choice' of university course, and entry to 'prestigious universities'.

Bolstering and self-promotion was also evident in communicating the enviable position of the school and the outstanding equipment and infrastructure offered. Another bolstering strategy was to refer to the school's prestigious location. This was most prominent in Sydney-based schools, though prospectuses from other States also 
frequently referred to location: "Situated on 16 hectares of landscaped grounds it is within walking distance of some of Perth's finest beaches" (Anglican girls school, WA). Text promoting geographic location was often accompanied by large, wideangle photographs of views from the school.

Descriptions of modern, state-of-the-art equipment and capital works were also uniform across prospectuses, including "a gallery space as an acoustically sensitive rehearsal and performance venue" (non-denominational, co-ed school, NSW) and "a 50-metre swimming pool, diving pool and junior pool... all of which are located within the school grounds" (Anglican girls school, WA).

Partial Reporting. The rhetorical strategy of partial reporting refers to taking a statistic or result out of a larger context. Many single sex schools cited neurological and educational research relating to "biologically programmed sex differences" to espouse the virtues and "powerful advantages" of being immersed in a single-sex educational environment. We identified this strategy as partial reporting since the degree to which achievement advantages arise from single-sex schooling remains unresolved. Differences found in many studies are often accounted for by selection bias and findings vary substantially across countries and educational contexts. References to recent neurological and educational research is an example of how a rhetorical strategy can frame the justification/legitimization of an action (Vaara 2002) - in this case, a decision to follow a single sex education model. It is likely this decision was taken many decades previously, but given ongoing debates about the benefits of single-sex versus mixed-sex education, many schools attempt to leverage advantage from 'evidence-based' arguments. The following example illustrates partial reporting:

Fewer than 2\% of American women have ever attended any single-sex school, public or private. However, more than 20\% of the women in the 
United States Congress... have attended single-sex schools. Thus, women who attend single-sex schools are about an order of magnitude more likely to serve in the House or Senate than would be expected based on their numbers. (Catholic girls school, NSW)

While most co-educational schools were silent on the issue of conferred benefits of a mixed-sex educational environment, a few navigated this contentious theme through discussions of a "phased co-educational environment", whereby schools were able to bring together "the best teaching practices of both single-sex and co-educational learning” (non-denomination, co-educational school, NSW).

Self-expansion. Self-expansion was used to suggest the school's influence was pervasive and permanent. First, schools made truth claims about their role in forming students' characters: “As we linked arms and sang out 'The Holiday Hymn' at that final end of year Mass and streamed out in to the world, we were leaving behind a crucible in which we had been formed and fired" (Catholic girls school, NSW). Second, schools often suggested they were like "family", being able to provide high levels of "nurturing", "support" and a "personal approach". Third, self-expansion was highly evident in descriptions of what schools could provide beyond formal or traditional educational parameters. Claims were made in catering to the "all round development" of the child, "incorporating learning, spiritual, physical and recreation experiences". As one prospectus claimed: "We give our children more than an education - we give them a wonderful start in life" (Jewish, co-educational school, NSW).

Reframing and reversal. The final rhetorical strategy identified was reframing and reversal, meaning 'an ironic or surprising shift to create a new idea' (Cheney et al 2004). Inner city schools, attempting to refute parental concerns about potentially negative aspects of urbanised education environments, highlighted the school's 
proximity to "contemporary artworks, public sculpture and architecture", "worldclass facilities" and "civic, business, legal and commercial centres", while providing “a quiet oasis of College life”.

Another example of reframing and reversal was to simultaneously rationalize the school as a corporate interest, in the context of broader fiscal pressures and policies, while denying the exclusivity of the school in terms of access. Prospectuses described 'Foundations', 'Trusts' and 'Funds', which raised money for large infrastructure projects outside schools budgets, as well as bursaries and scholarships. These entities were consistently associated with non-corporate themes, such as "securing the school's future", "protecting independence” and "it's all about the girls".

Several schools provided justifications for their high tuition fees and other costs, such as a Sydney girls school which charged fees over $\$ 25,000$ per annum and who suggested that its school board based its fee structure on three broad principles: "Fees as low as possible; fairness to all; and equity across generations of students".

Other schools, implicitly denying the socio-economic advantage necessary for enrolment and acceptance, pointed out their inclusiveness in terms of diverse student groups. Several schools suggested their students came from "all over Sydney" while others from across the States suggested they were inclusive of "people from all backgrounds" and "all kinds of families" and not "dominated by boys from any one district".

\section{Discussion}

This study provided examples of rhetorical strategies used by schools in the context of changing educational platforms and emphases. The appearance and 'feel' of the prospectuses themselves were an effective strategy in exuding status and prestige. At 
the same time, schools carefully denied that they were exclusionary through the use of reversal and reframing, most notably through their inclusivity and/or commitment to diversity, the accessibility of their locations, and the diversity of religious and cultural backgrounds of the student body.

Cheney et al (2004) suggests corporate rhetoric has two primary functions: it draws on existing cultural assumptions to legitimize or delegitimize particular policies, and, importantly, reproduces and reinforces cultural assumptions on which it is based. This study demonstrated that the successful deployment of rhetoric is both contingent on, and perpetuates, dominant discourses of educational privatization and marketisation. While the language of privatisation and marketisation was not always overtly present in the prospectuses, the vocabulary of choice, improvement, quality, effectiveness and efficiency (Ball and Youdell 2009) was clearly evident. Effectiveness and efficiency, as well as competition, were reflected in the shameless self-promotion of consistently high academic achievement records of students and the virtual certainty of securing university entrance, as well as in the partially reported, but purportedly evidencebased superiority of a single-sex education environment. Overt corporate language was carefully avoided in the prospectuses, lest the school be seen as self-serving, while messages indicating their broader value to the community were frequent.

The shrouding of business-like concepts in more palatable pedagogical terms is an illustration of how, as scholars such as Bourdieu and Fairclough have highlighted, language and semiosis works to construct and reconstruct neo-liberalism (Kuronen et al. Vaara, 2005) by 'writing out' wealth and privilege and other social forces, in shaping identity and 'success'. Hence, rhetorical strategies contribute to broader ideologies around economic and social privilege and normalise and maintain class values and power relations. The way prospectuses navigated the fine line between 
privatization and 'public good' discourses, which surely presents schools with an ambivalent position and a challenge in presenting coherent messages, also raises a point made by Watson (1995: 818). He argues that organizational actors might sometimes prefer to play a certain language game but be forced by circumstances to operate in another, or to 'switch between vocabularies' from two discourses as they try to 'make sense of, and get by in an organization'.

The language of 'quality' was evident in schools' bolstering strategy of communicating their prestigious locations and high-tech, state-of-the-art infrastructure and facilities. Indeed, superior facilities are likely to be a major selling point for private education. The disparity between facilities available in public and private schools was illustrated recently in a round of exceptional educational infrastructure spending by the Australian Commonwealth government. The allocation of $\$ 537$ million of funding for additional buildings and equipment to some of Australia's 'wealthiest private schools' (Bita 2009) prompted substantial media critique and public concern. This suggests that despite apparently widespread acceptance of funding models which provide substantial public resources to private schools, there exists pockets of resistance to some discourses which support the marketisation and privatization of education. Hence, while the discourse of privatization is privileged to the extent that it carries with it unquestioned premises of individual incentives, economic efficiency and smooth management (Cheney et al. 2004), its dominance is only secured as part of an ongoing struggle among competing discourses that are continually reproduced or transformed through communicative practices, and where the possibility for resistance always exists (Clegg 1989; Grant and Hardy 2003; Hardy 2001). 
This study represents only one avenue of examining organizational rhetoric and even within the context of education, offers only selected insights into the way rhetoric is shaped and used. For example, while an analysis of organizational communications provides information about the rhetorical messages which appear on its pages, we did not explore, as much consumer research does, the way persuasion techniques influenced current or prospective clients. Neither did our study examine the potentially important processes by which rhetorical strategies in the prospectuses evolved - for example, which cultural and local discourses were deemed important; how decisions were taken and enacted; and the dialogue between organizational actors and outside 'experts'. Future research could therefore usefully adopt multiple analytical levels (see Alvesson and Karreman 2000) to study rhetorical discourse and therefore further understandings of organizational persuasion, both as an outcome and a process.

Despite these limitations, we have demonstrated rhetorical analysis as an effective tool for critically scrutinizing the types of organizing principles which are calculated to persuade or influence an audience toward some end (Cheney et al. 2004; Kuronen et al. 2005). As well as identifying specific examples of strategies used by Australian schools in their prospectuses, we have highlighted some of the tensions facing contemporary organizations in communicating to various audiences, such as those between univocality and responsiveness and adaptiveness. We examined rhetorical strategies in a sector associated with multiple, competing and emerging discourses as ongoing educational debates continue. Consequently, the educational context provides rich terrain in which the connections between 'micro-discursive analyses' (Symon 2005) of corporate communications, and macro-discourses in social, political and cultural contexts, are made visible. 


\section{References}

Allan, A. J. (2009) 'The important of being a 'lady': Hyper-femininity and heterosexuality in the private, single-sex primary school', Gender and Education 21(2): 145-158.

Allen, B. J. (2004) Difference matters: Communicating social identity. Prospect Heights IL: Waveland Press.

Alvesson, M. and D. Karreman (2000) 'Taking the linguistic turn in organizational research: Challenges, responses, consequences', Journal of Applied Behavioral Science 36(2): 136-158.

Ball, S. and Youdell, D. (2009) 'Hidden privatisation in public education', Education Review 21(2): 73-83.

Bita, N. (2009) 'Labor's largesse to private primary schools', The Australian, June 19: p.1.

Brighouse, H. (2000) School choice and social justice. Oxford: Oxford University Press.

Cheney, G., Thoger Christensen, L., Conrad, C. and Lair, D. (2004) 'Corporate rhetoric as organizational discourse', in C. Oswick, L. Putnam, C. Hardy, N. Phillips and D. Grant (eds) The sage handbook of organizational discourse. London: Sage.

Clegg, S. (1989). Frameworks of power. London: Sage.

Cribb, A. and Ball, S. (2005) 'Towards an ethical audit of the privatisation of education', British Journal of Educational Studies 53(2): 115-128.

Davidson-Harden, A. and Majhanovich, S. (2004) 'Privatisation of education in Canada: A survey of trends', International Review of Education 50: 263-287.

Ezzamel, M. \& Willmott, H. (2008) "Strategy as discourse in a global retailer: A supplement to rationalist and interpretive accounts', Organization Studies 29(2): 191217.

Grant, D. and Hardy, C. (2003) 'Introduction: Struggles with Organizational Discourse', Organization Studies 25(1): 5-13.

Hardy, C. (2001) 'Researching organizational discourse', International Studies of Management and Organization 31(3): 25-47.

Hartley, D. (2008) 'Education, markets and the pedagogy of personalisation', British Journal of Educational Studies 56(4): 365-381.

Kuronen, M., Tienari, J. and Vaara, E. (2005) 'The merger storm recognizes no borders: An analysis of media rhetoric on a business manoeuvre', Organization 12(2): 247-273.

Kwong, J. (2000) 'Introduction: Marketization and privatization in education', International Journal of Educational Development 20: 87-92.

Legge, K. (1995) Human Resource Management: Rhetoric and Reality. London: Macmillan.

Linstead, S. (2001) 'Rhetoric and organizational control: A framework for analysis', in R. Westwood and S. Linstead (eds), The language of Organization. London: Sage.

Marginson, S. (1993) 'From cloister to market: The new era in higher education', Journal of Tertiary Education Administration, 15(1): 43-63.

Meadmore, D. and Meadmore, P. (2004) 'The boundlessness of performativity in elite Australian schools', Discourse: Studies in the cultural politics of education, 25(3): 375-387.

Rose, G. (2001) Visual methodologies: An introduction to the interpretation of visual materials. London: Sage. 
Swales, J. M. and Rogers, P. S. (1995) 'Discourse and the project of corporate culture: The Mission Statement', Discourse \& Society 6(2): 223-242.

Symes, C. (1998) 'Education for sale: A semiotic analysis of school prospectuses and other forms of educational marketing', Australian Journal of Education 42(2): 133152.

Tooley, J. (2003) 'Why Harry Brighouse is nearly right about the privatisation of education', Journal of Philosophy of Education 37(3): 427-447.

Warnick, B. (2000) 'Two systems of invention: The topics in the rhetoric and in the new rhetoric', in G. Gross and A. Walzer (eds), Rereading Aristotle's rhetoric. pp. 107-129. Carbondale: Southern Illinois University Press. 